\title{
Comparison of Plasma Oxidative Biomarkers and Conformational Modifications of Hemoglobin in Patients With Diabetes on Hemodialysis
}

\author{
Hadi Ansarihadipour ${ }^{1, *} ;$ Hamidreza Dorostkar $^{2}$ \\ ${ }^{1}$ Department of Biochemistry and Genetics, Arak University of Medical Sciences, Arak, IR Iran \\ $2^{2}$ Student Research Committee, Arak University of Medical Sciences, Arak, IR Iran \\ ${ }^{*}$ Corresponding Author: Hadi Ansarihadipour, Department of Biochemistry and Genetics, Arak University of Medical Sciences, Arak, IR Iran. Tel: +98-8634173502, Fax:+98-8634173529, \\ E-mail: ansari@arakmu.ac.ir
}

Received: July 15, 2014; Revised: September 15, 2014; Accepted: October 6, 2014

\begin{abstract}
Background: Diabetes is associated with an increased generation of reactive oxygen species (ROS), which plays an important role in the development of oxidative stress and anemia.

Objectives: The main purpose of this study was to investigate whether patients with diabetes undergoing hemodialysis (HD) were susceptible to oxidative stress and whether resulting damages affect the structure of hemoglobin (Hb) and plasma proteins.

Patients and Methods: Twenty patients with diabetes undergoing HD, 20 patients with diabetes and normal renal function, and 20 ageand sex-matched healthy subjects were included in this study. Methaemoglobin (Met-Hb), hemichrome and conformational changes of $\mathrm{Hb}$ were analyzed as oxidative markers in erythrocytes. Ferric reducing ability of plasma (FRAP) and protein carbonyl content (PCO) were determined as plasma oxidative biomarkers. Also triglyceride, cholesterol, albumin, blood urea nitrogen (BUN), creatinine, glucose and uric acid were assayed as biochemical parameters of plasma.

Results: Patients with diabetes undergoing hemodialysis had significantly lower levels of PCO and albumin $(\mathrm{P}<0.05)$, but significantly higher levels of FRAP, BUN, creatinine and uric acid $(\mathrm{P}<0.05)$ as compared to patients with diabetes and normal renal function. Linear regression analysis showed significant negative correlations between PCO and FRAP $(r=-0.53)$, oxy- $\mathrm{Hb}(\mathrm{r}=-0.88)$ and $\mathrm{Hb}$ absorbance at 340 $\mathrm{nm}(\mathrm{r}=-0.79), 420 \mathrm{~nm}(\mathrm{r}=-0.85)$ and $577 \mathrm{~nm}(\mathrm{r}=-0.68)$ in patients with diabetes undergoing hemodialysis. Also PCO was significantly and positively correlated with $\mathrm{Hb}$ absorbance at $275 \mathrm{~nm}(\mathrm{r}=0.63)$ and $560 \mathrm{~nm}(\mathrm{r}=0.61)$ which confirmed the oxidative damage to erythrocytes in control subjects.

Conclusions: Hemodialysis exacerbates oxidative stress and conformational changes of $\mathrm{Hb}$ in patients with diabetes on hemodialysis. The FRAP value can be used as a positive determinant, while PCO and $\mathrm{Hb}$ derivatives can be used as negative determinants of oxidative stress in patients with diabetes.
\end{abstract}

Keywords:Hemodialysis; Hemoglobin; Oxidative Stress; Plasma

\section{Background}

According to the World Health Organization (WHO) reports, 347 million people worldwide have diabetes (1, 2). In 2010, an estimated 3.4 million people died from consequences of high fasting blood sugar (3). The World Health Organization has evaluated that diabetes will be the 7th leading cause of death in 2030 (4). Diabetes is among the risk-factors of heart disease, stroke (5), blindness (6) and kidney failure (4). Diabetic nephropathy is the leading cause of end-stage renal disease (ESRD) in many countries. End-stage renal disease can be defined by the requirements for kidney transplantation or maintenance hemodialysis (7). Patients on hemodialysis have increased risk of cardiovascular morbidity and mortality (8). Oxidative stress occurs when the balance between reactive oxygen species (ROS) production and antioxidant capacity is disrupted. Reactive oxygen species are neutralized by endogenous and exogenous antioxidants such as glutathione (GSH), nicotinamide adenine dinu- cleotide phosphate (NADPH), antioxidant enzymes and vitamins. Natural products of plant origin (nutraceuticals) have been proposed as a potential source of natural antioxidants with pharmaceutical activity (9-11). Also the therapeutic effects of nutraceuticals for curing kidney dysfunction are being studied (12). Elevated oxidative stress and reduced antioxidant defense systems in patients with diabetes and ESRD accelerate the prevalence of chronic complications such as hemolysis. Anemia is strongly predictive of complications and death from cardiovascular causes in patients with chronic kidney disease (13). Therefore anemia is associated with mortality, hospitalization and health-related quality of life (QoL) measures of patients on hemodialysis. Effective anemia management is an essential component for the treatment of patients with chronic kidney disease (CKD) (14). The relationship between ROS production and hemodialysis could play an important role in $\mathrm{Hb}$ oxidation

Copyright ( ) 2014, Iranian Red Crescent Medical Journal. This is an open-access article distributed under the terms of the Creative Commons Attribution-NonCommercial 4.0 International License (http://creativecommons.org/licenses/by-nc/4.0/) which permits copy and redistribute the material just in noncommercial usages, provided the original work is properly cited. 
and met-Hb production, in which the iron is in the ferric $\left(\mathrm{Fe}^{3+}\right)$ state and cannot bind to oxygen. MetHb due to its pseudo-peroxidase activity produces ROS in erythrocytes which correlated well with osmotic fragility and hemolysis. Our previous studies showed that spectral analysis denotes if the heme and globin groups are present in normal conditions or take irregular forms of $\mathrm{Hb}$ as a result of oxidative stress $(15,16)$.

\section{Objectives}

The purpose of this study was to assess the oxidative status of plasma and erythrocytes in patients with diabetes on life-saving hemodialysis. This work was also interested in investigating the conformational changes in $\mathrm{Hb}$, oxidative modifications of proteins and antioxidant capacity of plasma.

\section{Patients and Methods}

\subsection{Patients}

According to our previous studies on spectral and structural changes of $\mathrm{Hb}$ (15 and 16), the confidence level specified was 95\% (0.95 probability), the associated Z-value was $1.96, d=0.22$ and $\mathrm{p}=\mathrm{q}=0.5$. The required sample size for this study was: $\mathrm{n}=\mathrm{Z}_{\alpha / 2}{ }^{2} \mathrm{pq} / \mathrm{E}^{2}=(1.96)^{2}(0.5)^{2} / 0.22=$ $19.85 \approx 20$. Therefore, 20 patients with diabetes undergoing maintenance hemodialysis, 20 patients with diabetes and normal renal function hemodialysis, and 20 control subjects (10 men and 10 women in each group) from Valieasr hospital in Arak, Iran between 2013/9/1 and 2014/5/1 were included in this case-control study. According to the inclusion and exclusion criteria, 60 subjects were included in and no one was excluded from this study. Anticoagulated (EDTA treated) whole blood was collected from patients and control subjects who had given informed consent with the approval of the Human Ethics Committee of Arak University of Medical Sciences in accordance with the ethical guidelines of the 1975 Declaration of Helsinki. The biochemical parameters were measured in the dialysis section of Valieasr hospital in Arak University of medical sciences. Structural analysis of $\mathrm{Hb}$, ferric reducing ability of plasma (FRAP) assay and PCO was measured at the department of biochemistry and genetics, at the faculty of medicine in Arak University of Medical Sciences.

\subsection{Chemicals and Equipment}

All basic reagents were from the Merck Company (Germany) unless indicated otherwise. All reagents used were of analytical reagent grade. Spectrophotometer 6505 UV/V was from JENWAY, pH meter from METTLER, centrifuge $5804 \mathrm{R}$ from Eppendorf, balance from Sartorius, micropipettes from SOCOREX, glassware from LASSCO and pipettes from ISOLAB. All equipment was calibrated with control solutions and serum controls according to standard protocols for each method.

\subsection{Biochemical Parameters}

Biochemical parameters were analyzed by using laboratory techniques for triglyceride (enzymatic, lipase), cholesterol (enzymatic, cholesterol oxidase), albumin (colorimetric, bromocresol green), blood urea nitrogen (BUN) (enzymatic, urease and glutamate dehydrogenase), creatinine (colorimetric, Jaffe), glucose (enzymatic, glucose oxidase) and uric acid (enzymatic, uricase).

\subsection{Ferric Reducing Ability of Plasma Assay}

The total antioxidant capacity of plasma was measured according to the method introduced by Benzie and Strain (17). Briefly, working FRAP reagent was prepared by mixing acetate buffer $(300 \mathrm{mM}, \mathrm{pH}=3.6), 2$, 4, 6- tri [2-pyridyl]-s-triazine (10 $\mathrm{mM}$ in $40 \mathrm{mM} \mathrm{HCl}$ ) solution and $\mathrm{FeCl}_{3}(20 \mathrm{mmol} / \mathrm{L})$ solution in a 10:1:1 ratio, respectively. The FRAP assay reagent was mixed with plasma and the absorbance was read at $593 \mathrm{~nm}$.

\subsection{Protein Estimation}

Protein content of all samples was estimated by measuring the optical density at $280 \mathrm{~nm}$, using bovine serum albumin as the standard. Plasma proteins were then analyzed for carbonyl content.

\subsection{Carbonyl Assay in Plasma Proteins}

The PCO was estimated using a modified version of the method described by Evans et al. (18). Briefly, to a tube containing $100 \mu \mathrm{L}$ of plasma, $500 \mu \mathrm{L}$ of $10 \mathrm{mM} \mathrm{2,4-dini-}$ trophenylhydrazine (DNPH) in $2 \mathrm{M} \mathrm{HCl}$ was added. After incubation, $600 \mu \mathrm{L}$ of $20 \%$ trichloroacetic acid (TCA) was added to each tube sample and the tubes were centrifuged (3000 r/minute, 3 minutes). The pellets were washed with ethanol-ethyl acetate solution and dissolved in guanidine hydrochloride solution. Carbonyl content was calculated from the maximum absorbance (at 360$390 \mathrm{~nm}$ ) using a molar absorption coefficient of 22,000/ Mcm.

\subsection{Erythrocyte Washing and Lysis}

Erythrocytes were suspended in 15 volumes of 100 $\mathrm{mmol} / \mathrm{L}$ cold isotonic phosphate buffer, $\mathrm{pH}=7.4$ and centrifuged at $3000 \mathrm{r} / \mathrm{minute}$ for 10 minutes, at $4^{\circ} \mathrm{C}$. Packed cells were washed three times with isotonic phosphate buffer and buffy coat was removed carefully. Erythrocytes were lysed with 15 volume of cold hypotonic $5 \mathrm{mmol} / \mathrm{L}$ phosphate buffer, $\mathrm{pH}=7.4$.

\subsection{Hemoglobin Assay}

Hemoglobin concentration was estimated on the basis of Drabkin's method. Briefly, $20 \mu \mathrm{L}$ of the hemolysate was added to $5000 \mu \mathrm{L}$ of Drabkin reagent $\left(0.03 \% \mathrm{~K}_{3}\left[\mathrm{Fe}(\mathrm{CN})_{6}\right]\right.$, $0.1 \% \mathrm{NaHCO}_{3}, 0.005 \% \mathrm{KCN}$ ), incubated for 15 minutes; then, the absorbance was measured at a wavelength of $540 \mathrm{~nm}$. 


\subsection{Determining the Oxidative Modifications of Hemoglobin}

Erythrocyte samples were placed on ice and $\mathrm{Hb}$ concentration was adjusted to $4 \times 10^{-5} \mathrm{~mol} / \mathrm{L}$ with phosphate buffer and absorbance of each sample was measured at 275, 350, 420, 560 and 577 nanometers. Also, micromolar concentrations of oxy-Hb and met-Hb were calculated according to the following equations (19):

$$
\begin{aligned}
& \text { Oxy-Hb }=-89 A_{560}+119 A_{577}-39 A_{630} \\
& \text { Met-Hb }=-55 A_{560}+28 A_{577}+307 A_{630}
\end{aligned}
$$

Where $\mathrm{A}$ is the absorbance of $\mathrm{Hb}$ at indicated wavelengths.

\subsection{Investigating Spectral Changes}

The sum of oxy-Hb and met-Hb concentrations should remain constant during the course of incubation. If not, the reaction was assumed more complex and optical densities at more wavelengths including 350, 420 and 542 nanometers were considered (20).

\subsection{Providing the Data Source}

The data sources were provided and drawn by Microsoft office Excel 2007.

\subsection{Statistical Methods}

All samples and standards were run in duplicate and the results are presented as mean \pm SD. The data was analyzed by the SPSS software version 20 . Statistical significance at the 0.05 level was determined by paired samples t-test and one-way ANOVA method of multiple comparisons. Homogeneity of variances was performed by the Leven test and post hoc multiple comparisons with Tukey's method. In addition, Pearson's correlations and linear regression analyses were performed to explore relationships between the oxidative parameters.

\subsection{Foundation Project}

This work was supported by the Arak University of Medical Sciences (grant No. 911) and the Human Ethics committee in Medical Research (No. 92-146-6).

\section{Results}

\subsection{Biochemical Parameters}

Demographic and biochemical parameters of all groups are shown in Table 1. Patient and control groups were matched for sex and age and did not differ significantly from each other with respect to sex (10 men and 10 women), age (58 \pm 5 years), triglyceride and cholesterol. When compared with the control and diabetic groups, patients with diabetes undergoing hemodialysis had statistically higher levels of BUN, creatinine and uric acid but lower levels of albumin.

\subsection{Ferric Reducing Ability of Plasma Assay}

Baseline oxidative stress and antioxidant parameters are shown in Table 2. When compared with the control and diabetic groups, patients with diabetes undergoing hemodialysis had statistically higher levels of FRAP, an indicator of antioxidant power of plasma (1330 \pm 150 vs. $1040 \pm 120$ and1020 \pm 170 , respectively).

\subsection{Carbonyl Assay in Plasma Proteins}

In patients with diabetes on hemodialysis the percentage ratios of carbonyl content, BUN, creatinine and albumin to FRAP values were significantly different from controls and patients with diabetes $(\mathrm{P}<0.05)$. Protein carbonyl content, an indicator of oxidative protein damage, in plasma of patients with diabetes on hemodialysis was significantly lower than patients with diabetes (3.66 \pm 0.95 vs. $4.71 \pm 0.72$ ). In patients with diabetes on hemodialysis the percent ratios of carbonyl content to BUN, creatinine and uric acid were significantly lower than controls and patients with diabetes $(\mathrm{P}<0.05)$. There was a significant negative correlation between PCO of plasma and oxy-Hb concentration $(r=-0.71)$, which indicated the reduced oxygen transport in patients with diabetes on hemodialysis (Figure $2 \mathrm{D}$ ). Also there was a significant negative correlation between PCO of plasma and FRAP values $(r=-0.53)$, which indicated the reduced antioxidant power of plasma in patients with diabetes on hemodialysis (Figure $3 \mathrm{C}$ ).

\begin{tabular}{lccc}
\hline Table 1. The Demographic and Biochemical Characteristics of the Patients and Control Subjects $(\mathrm{n}=20)^{\mathrm{a}, \mathrm{b}, \mathrm{c}}$ \\
\hline Biochemical Characteristics & Control Group & Patients With Diabetes & Patients With Diabetes on Hemodialysis \\
\hline Triglyceride, mg/dL & $153 \pm 60$ & $143 \pm 55$ & $142 \pm 85$ \\
Cholesterol, mg/dL & $172 \pm 28$ & $163 \pm 36$ & $146 \pm 33$ \\
Albumin, g/dL & $4.5 \pm 0.2$ & $4.52 \pm 0.49$ & $3.86 \pm 0.46^{\mathrm{d}, \mathrm{e}}$ \\
BUN, mg/dL & $11.5 \pm 2$ & $13.8 \pm 3$ & $53.6 \pm 15^{\mathrm{d}, \mathrm{e}}$ \\
Creatinine, mg/dL & $1.2 \pm 0.1$ & $1.1 \pm 0.2$ & $7 \pm 1.6^{\mathrm{d}, \mathrm{e}}$ \\
Glucose, $\mathbf{m g} / \mathbf{d L}$ & $107 \pm 8$ & $154 \pm 39^{\mathrm{e}}$ & $151 \pm 70^{\mathrm{d}}$ \\
Uric acid, $\mathbf{m g} / \mathbf{d L}$ & $4.64 \pm 0.99$ & $4.73 \pm 1.15$ & $6.44 \pm 1.35^{\mathrm{d}, \mathrm{e}}$
\end{tabular}

\footnotetext{
a abbreviations: BUN, blood urea nitrogen.

$\mathrm{b}$ Data are presented as Mean \pm SD.

c Data are for 10 women and 10 men in $58 \pm 5$ years.

$\mathrm{d}_{\mathrm{P}}<0.05$ vs. control subjects.

$\mathrm{e}_{\mathrm{P}}<0.05$ vs. patients with diabetes.
} 
Ansarihadipour Het al.

\begin{tabular}{lccc}
\hline \multicolumn{4}{l}{ Table 2. The Parameters of Oxidative Stress in the Patients and Control Subjects $(\mathrm{n}=20)^{\mathrm{a}} \mathrm{b}, \mathrm{c}$} \\
\hline & Control Group & Patients With Diabetes & Patients With Diabetes on Hemodialysis \\
\hline FRAP, uM & $1040 \pm 120$ & $1020 \pm 170$ & $1330 \pm 150^{\mathrm{d}, \mathrm{e}}$ \\
Carbonyl groups, nM/mg protein & $4.11 \pm 0.55$ & $4.71 \pm 0.72$ & $3.66 \pm 0.95^{\mathrm{e}}$ \\
Carbonyl groups/FRAP, \% & $0.39 \pm 0.09$ & $0.46 \pm 0.10^{\mathrm{d}}$ & $0.27 \pm 0.07^{\mathrm{d}, \mathrm{e}}$ \\
Glucose/FRAP,\% & $9.93 \pm 1.40$ & $15.32 \pm 5.16^{\mathrm{d}}$ & $11.15 \pm 5.24^{\mathrm{d}}$ \\
BUN/FRAP, \% & $1.08 \pm 0.23$ & $1.36 \pm 0.28$ & $3.98 \pm 1.33^{\mathrm{d}, \mathrm{e}}$ \\
Creatinine/FRAP, \% & $0.11 \pm 0.02$ & $0.11 \pm 0.02$ & $0.51 \pm 0.12 \mathrm{~d}, \mathrm{e}$ \\
Albumin/FRAP,\% & $0.42 \pm 0.05$ & $0.44 \pm 0.07$ & $0.29 \pm 0.06^{\mathrm{d}, \mathrm{e}}$ \\
Uric acid/FRAP, \% & $0.43 \pm 0.07$ & $0.45 \pm 0.08$ & $0.47 \pm 0.09$ \\
Carbonyl groups/glucose, \% & $3.80 \pm 0.63$ & $3.27 \pm 0.98$ & $2.71 \pm 0.97^{\mathrm{d}}$ \\
Carbonyl groups/BUN, \% & $37.04 \pm 8.37$ & $36.28 \pm 8.33$ & $7.27 \pm 2.74^{\mathrm{d}, \mathrm{e}}$ \\
Carbonyl groups/Creatinine, \% & $348.7 \pm 58.2$ & $445.0 \pm 110.0 \mathrm{~d}$ & $54.22 \pm 15.74^{\mathrm{d}, \mathrm{e}}$ \\
Carbonyl groups/albumin, \% & $91.57 \pm 13.62$ & $105.39 \pm 18.72$ & $95.12 \pm 30.10$ \\
Carbonyl groups/uric acid, \% & $92.79 \pm 24.50$ & $106.78 \pm 32.84$ & $60.65 \pm 24.10^{\mathrm{d}, \mathrm{e}}$ \\
\hline
\end{tabular}

d $\mathrm{P}<0.05$ vs. control subjects

$\mathrm{e}_{\mathrm{P}}<0.05$ vs. patients with diabetes.

a Abbreviations: FRAP, ferric reducing ability of plasma; BUN, blood urea nitrogen.

$\mathrm{b}$ Data are presented as mean $\pm \mathrm{SD}$.

${ }^{\mathrm{C}}$ Data are for 10 women and 10 men in $58 \pm 5$ years.

Figure 1. Flow Chart Summarizing the Study Design

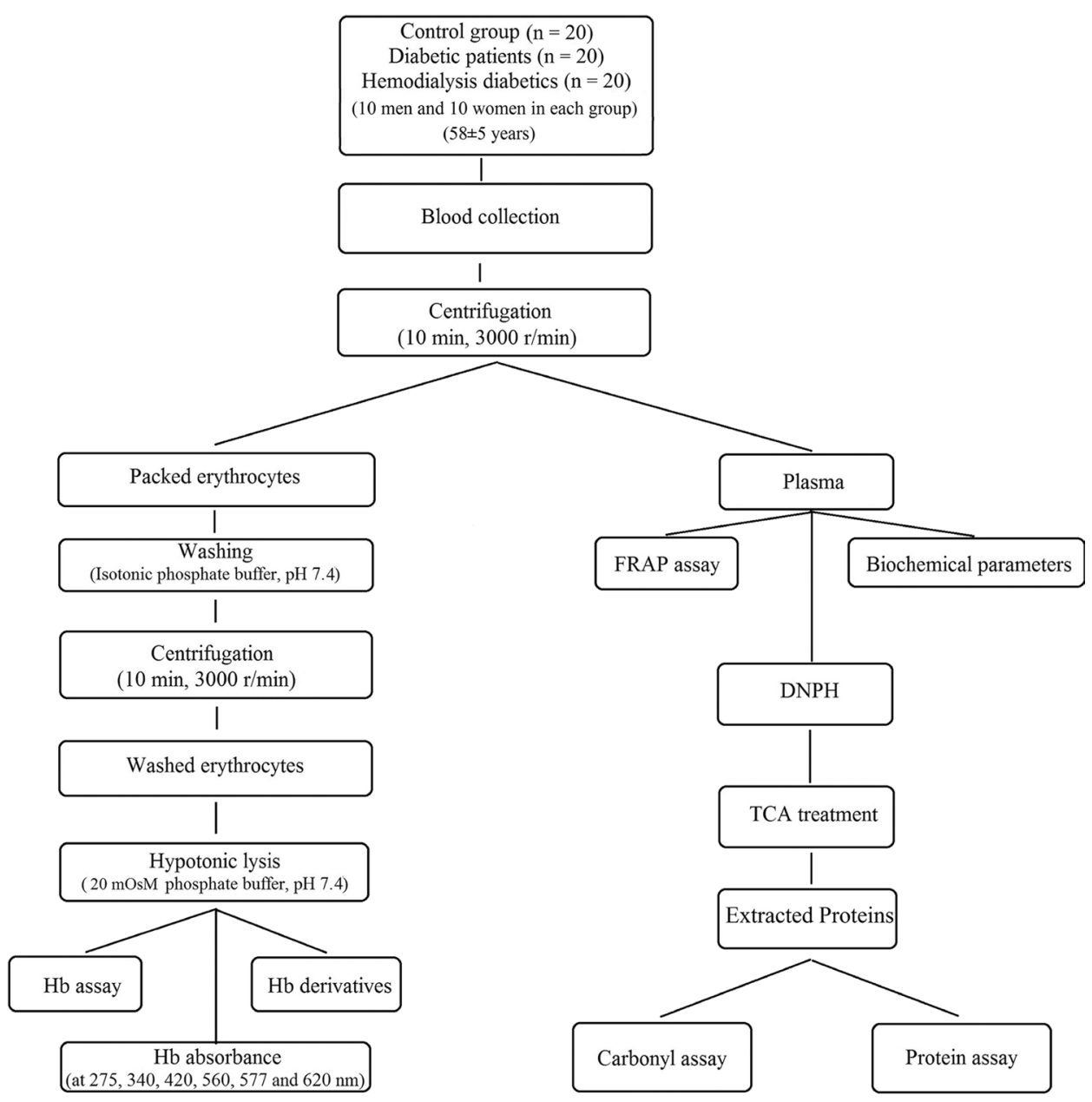

FRAP, ferric reducing ability of plasma; $\mathrm{g}$, centrifugal force; $\mathrm{Hb}$, hemoglobin; $\mathrm{n}$, total number of subjects; $\mathrm{nm}$, nanometer; TCA, trichloroacetic acid. 


\subsection{Oxidative Modifications of Hemoglobin}

Relationships among plasma PCO and Hb absorbance at different wavelengths were significant. There was a significant negative correlation between PCO of plasma and $\mathrm{Hb}$ absorbance at $340 \mathrm{~nm}, 420 \mathrm{~nm}$ and $577 \mathrm{~nm}$ (Figure 2), yet a positive correlation at $560 \mathrm{~nm}(\mathrm{r}=0.61)$ (Figure 3). Decrement in absorbance band at $340 \mathrm{~nm}(\mathrm{r}=-0.79)$ refers to the weakness of the non-covalent bond between heme iron and the histidine residue (Figure $2 \mathrm{~A}$ ). Increase in PCO of plasma was significantly correlated with decrease in absorbance at $577 \mathrm{~nm}(\mathrm{r}=-0.68)$, which indicates the reduced concentrations of oxy-Hb in patients with diabetes and long-term hemodialysis (Figure $2 \mathrm{C}$ ). Considering the Soret band (420 nm), which corresponds to the heme-heme interaction, there was a significant decrease in absorbance values $(\mathrm{r}=-0.85)$ in patients with diabetes undergoing hemodialysis (Figure $2 \mathrm{~B}$ ). The $\mathrm{Hb}$ absorbance at $275 \mathrm{~nm}$ corresponds to the constant globin, and the half soret band width. The significant positive correlation between plasma PCO and absorbance values at 275 $\mathrm{nm}(\mathrm{r}=0.63)$ indicated the reduction in concentration of oxy-Hb in patients with diabetes undergoing hemodialysis (Figure $3 \mathrm{~A}$ ).

\section{Discussion}

Oxidative stress results from the excessive generation of ROS, which overwhelms antioxidant mechanisms. Altered nonenzymatic and enzymatic antioxidants were observed in ESRD patients on peritoneal dialysis (PD) and on hemodialysis (HD) (21-24). Our data have demonstrated that patients with diabetes on hemodialysis treatment exhibit profound alterations in their oxidative reactions and antioxidant mechanisms. We have clearly shown increased $\mathrm{Hb}$ oxidation, as measured by met-Hb production in patients with diabetes undergoing hemodialysis as compared to the control group and patients with diabetes with normal renal function. This is in argument with the results obtained for patients with diabetes and $\operatorname{ESRD}(22,25,26)$. Also our results confirmed the negative correlation between PCO of plasma and $\mathrm{Hb}$ absorbance at 340 and $420 \mathrm{~nm}$ in patients with diabetes undergoing hemodialysis, which indicates a higher degree of oxidative reactions. Decrement in absorbance band at $340 \mathrm{~nm}$ refers to the weakness of the non-covalent bond between heme iron and histidine residue. Many authors have shown a reduction in antioxidant enzymes in red blood count (RBC) of patients with chronic renal failure (CRF) (22, 25, 26). Zwolinska et al. explained a significant decrease in erythrocyte glutathione peroxidase (GSH-Px), catalase (CAT) and superoxide dismutase (SOD) activities in dialyzed children (27). In contrast, increased activity of erythrocyte-SOD and erythrocyte-GSH-Px has been observed by other researchers in patients on hemodialysis and peritoneal dialysis $(21,28,29)$. They described this fact by invoking adaptation to the increased rate of oxidative stress. Other study examined lipid peroxide and antioxidant enzymes in erythrocytes of ESRD patients
A

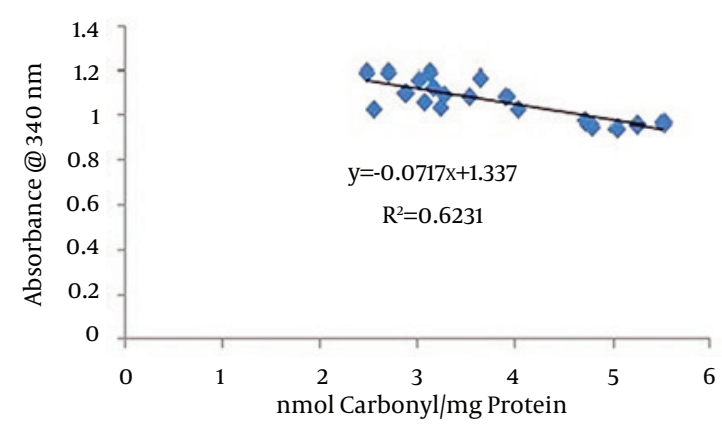

C

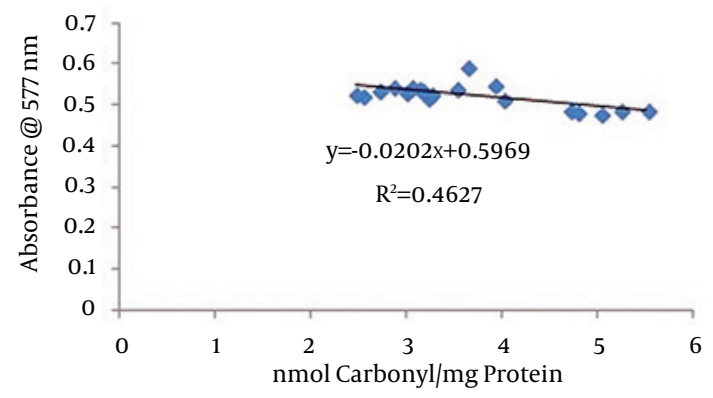

B

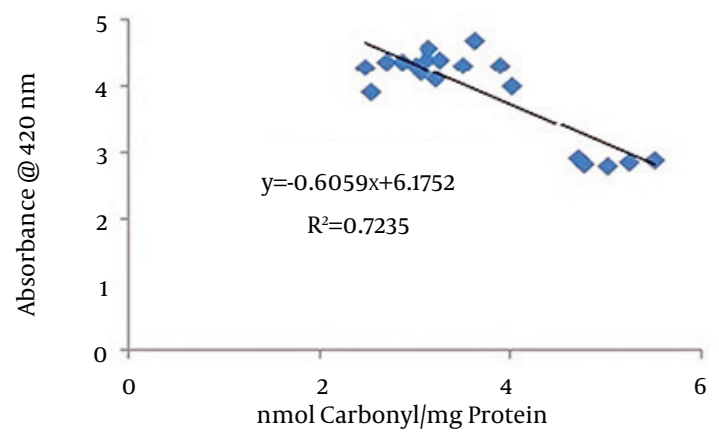

D

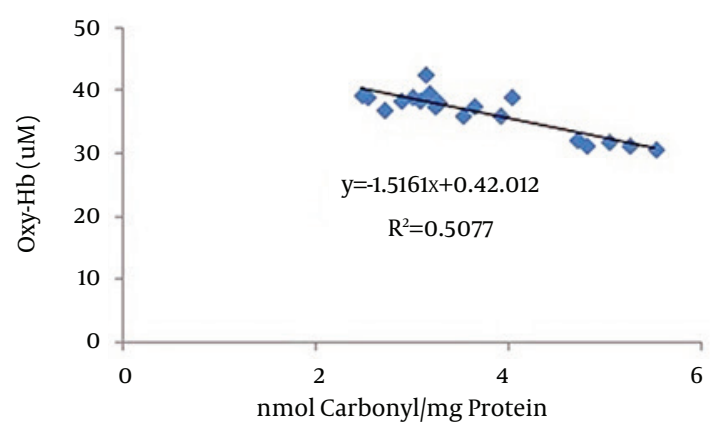

Figure 2. Significant Negative Correlations Between Protein Carbonyl and Hemoglobin Absorbance at A) $340 \mathrm{~nm}$; B) $420 \mathrm{~nm}$; C) $577 \mathrm{~nm}$ and D) oxy-Hb in patients with diabetes undergoing hemodialysis the correlation between variables was calculated by the Pearson's test. 
A

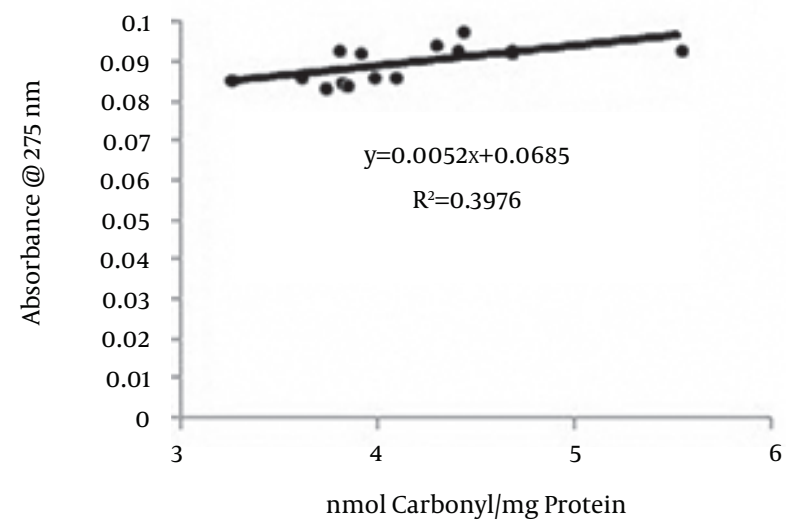

B

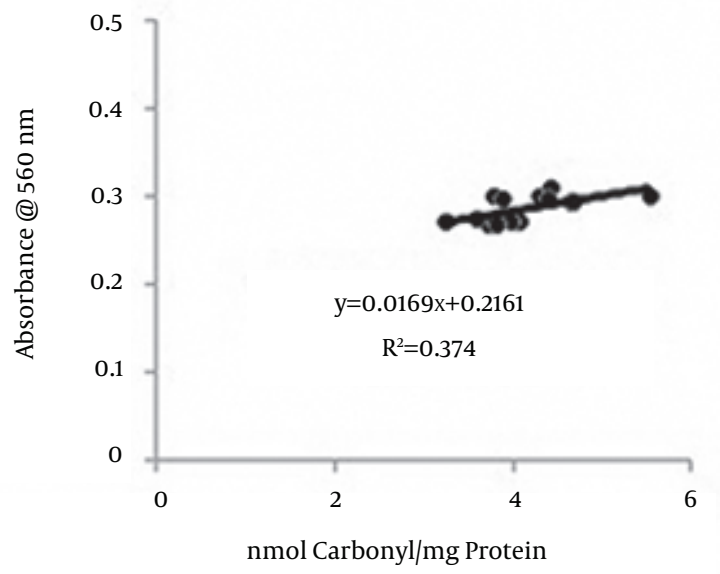

C

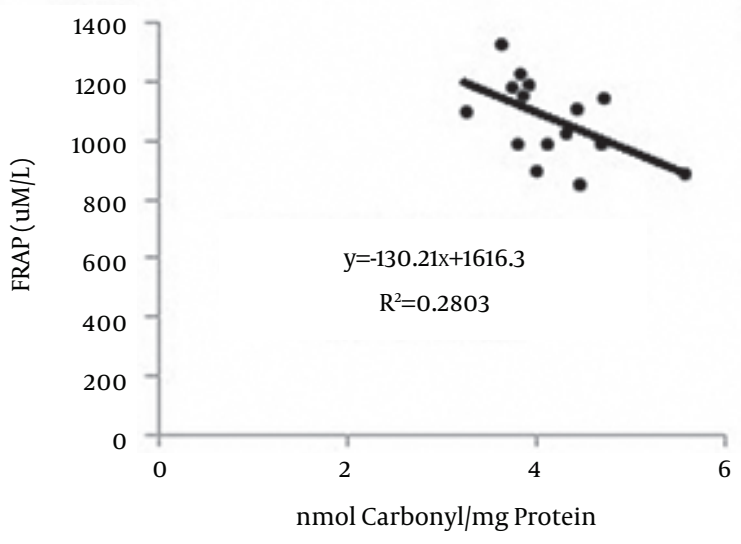

A) $275 \mathrm{~nm}$; B) $560 \mathrm{~nm}$ and C) FRAP in control subjects. The correlation between variables was calculated by the Pearson's test.

before and after HD. There was no significant change in any of the parameters. Chu et al. indicated that patients with high levels of plasma PCO before HD, exhibited a significant decrease in the carbonyl content, yet the concentration was still higher than normal (23). We observed high plasma levels of BUN and uric acid, which have antioxidant activity, in patients with diabetes on hemodialysis. Also lower concentrations of PCO were detected in patients on hemodialysis before HD sessions. Our results suggest the high intensity of antioxidant power of plasma. However, the limitation of our study is that we made single measurements of the oxidative parameters before hemodialysis, which ignores any variability in these parameters over time. Samouilidou et al. documented decreased plasma lipoprotein (LP) and total antioxidant capacity post HD session compared to those before HD (29).

The negative correlations found in our study between plasma PCO and FRAP values in the control group con- firms the diminished efficacy of antioxidant capacity of plasma. The data available from the literature concerning oxidative stress in patients on hemodialysis are contradictory. Samouilidou et al. demonstrated that patients on hemodialysis and peritoneal dialysis show a similar susceptibility to oxidative stress (29). In contrast, Van Biesen et al. underlined that oxidative stress appears to be higher in patients on hemodialysis than those on peritoneal dialysis (21). Similarly, other authors showed less severe LP in PD than in patients on hemodialysis $(30,31)$. Our results showed a 5-fold increase in plasma creatinine in patients with diabetes on hemodialysis as compared to the control group and patients with diabetes. However, one should consider that serum plasma creatinine might not fully indicate dialysis efficiency. Rather, the creatinine concentration reflects muscle mass, dietary habits and use of certain drugs. Also this work demonstrated a significant decrease in plasma albumin in patients 
with diabetes undergoing hemodialysis as compared to the control groups. Chu et al. described a link between increased oxidative stress, measured by PCO of plasma and acute phase inflammation in severe hypoalbuminemic hemodialysis patients (23). Kir et al. documented no significant change in plasma SOD levels before and after HD, but total lipid peroxide levels were increased after HD (32). On the other hand, Usberti et al. observed that a dialysis session increased plasma MDA, 4-hydroxynonenal and diminished plasma thiols (31). Oxidative stress plays an important role in progression of pathological conditions. Changes mediated by ROS are associated with atherosclerosis in children with chronic renal failure, causing a high rate of morbidity and mortality (30). In conclusion, the activity of nonenzymatic antioxidants is highly increased in plasma of patients with diabetes undergoing hemodialysis. Patients with diabetes and maintenance hemodialysis exhibit lower carbonyl content in plasma proteins as compared to control subjects and patients with diabetes and normal renal function. In contrast $\mathrm{Hb}$ oxidative modifications occur in patients with diabetes on hemodialysis. Overall these results indicate the oxidative susceptibility of erythrocytes in patients with diabetes on hemodialysis.

Innovations and breakthroughs: many of the protocols used to confirm oxidative damage are based on simplicity and ease of use rather than specificity in clinical diagnosis. Furthermore, many of the techniques employed to project oxidative stress do not yield precise and reliable results. The objective of this study was to establish a sensitive and quantitative algorithm of methods for estimating oxidative changes in plasma and erythrocytes. In the present research, spectrophotometric analysis indicated conformational modifications in $\mathrm{Hb}$. Of interest, there was a significant increase in the antioxidant power of plasma in patients with diabetes on hemodialysis. Also there was a significant negative correlation between protein carbonyl and $\mathrm{Hb}$ absorbance at different wavelengths and significant changes in PCO and some biochemical parameters. Results of this research are applicable in biochemical labs and in clinical settings as well as for designing of systems and methods for further investigations.

\section{Acknowledgements}

This research was supported by the Department of Biochemistry and Genetics and Student Research Committee of Arak University of Medical Sciences, Arak, Iran.

\section{Authors' Contributions}

Dr. Hadi Ansarihadipour developed the original idea, prepared the protocol, wrote the manuscript, contributed to the development of the protocol and was the guarantor. Hamidreza Dorostkar prepared the protocol and abstracted and analyzed the data. 1) Study concept and design: Dr. Hadi Ansarihadipour. 2) Acquisition of data: Dr. Hadi Ansarihadipour. 3) Analysis and interpretation of data: Hamidreza Dorostkar. 4) Drafting of the manuscript: Dr. Hadi Ansarihadipour. 5) Critical revision of the manuscript for important intellectual content: Dr. Hadi Ansarihadipour. 6) Statistical analysis: Hamidreza Dorostkar.

\section{Funding/Support}

The funding organizations were public institutions and had no role in the design and conduct of the study, collection, management, and analysis of the data or preparation, review and approval of the manuscript. The Department of Biochemistry and Genetics and Student Research Committee of Arak University of Medical Sciences provided practical support for the focus group and survey processes, including letters of endorsement, hospital contact information and assistance with logistic arrangements for focus group sessions.

\section{References}

1. Danaei G, Finucane MM, Lu Y, Singh GM, Cowan MJ, Paciorek CJ, et al. National, regional, and global trends in fasting plasma glucose and diabetes prevalence since 1980: systematic analysis of health examination surveys and epidemiological studies with 370 country-years and 2.7 million participants. Lancet. 2011;378(9785):31-40.

2. World Health Organization.. Media centre Diabetes. 2013. Available from: http://www.who.int/mediacentre/factsheets/fs312/en/.

3. Global health risks. Mortality and burden of disease attributable to selected major risks. Geneva: World Health Organization; 2009. Available from: www.who.int/healthinfo/global_burden_disease/GlobalHealthRisks_report_full.pdf.

4. Global status report on non communicable diseases. Geneva: World Health Organization; 2010. Available from: www.who.int/nmh/ publications/ncd_report_full_en.pdf.

5. Morrish NJ, Wang SL, Stevens LK, Fuller JH, Keen H. Mortality and causes of death in the WHO Multinational Study of Vascular Disease in Diabetes. Diabetologia. 2001;44 Suppl 2:S14-21.

6. Global data on visual impairments. Geneva: World Health Organization; 2010. Available from: www.who.int/blindness/GLOBALDATAFINALforweb.pdf.

7. White SL, Chadban SJ, Jan S, Chapman JR, Cass A. How can we achieve global equity in provision of renal replacement therapy? Bull World Health Organ. 2008;86(3):229-37.

8. Himmelfarb J, Hakim RM. Oxidative stress in uremia. Curr Opin Nephrol Hypertens. 2003;12(6):593-8.

9. Moein S, Moein M, Khoshnoud MJ, Kalanteri T. In vitro antioxidant properties evaluation of 10 Iranian medicinal plants by different methods. Iran Red Crescent Med J. 2012;14(12):771-5.

10. Asadi-Pooya AA, Nikseresht AR, Yaghoubi E. Old Remedies for Epilepsy: Avicenna's Medicine. Iran Red Crescent Med J. 2012;14(3):1747.

11. Khanahmadi M, Miraghaee S, Karimi I. Evaluation of the Antioxidant and antimicrobial Properties of Dorema aucheri plant. Iran Red Crescent Med J. 2012;14(10):684-5.

12. Al-Okbi SY, Mohamed DA, Hamed TE, Esmail R, Donya SM. Prevention of renal dysfunction by nutraceuticals prepared from oil rich plant foods. Asian Pac J Trop Biomed. 2014;4(8):618-27.

13. Weiner DE, Tighiouart H, Vlagopoulos PT, Griffith JL, Salem DN, Levey AS, et al. Effects of anemia and left ventricular hypertrophy on cardiovascular disease in patients with chronic kidney disease. J Am Soc Nephrol. 2005;16(6):1803-10.

14. Locatelli F, Pisoni RL, Combe C, Bommer J, Andreucci VE, Piera L, et al. Anaemia in haemodialysis patients of five European countries: association with morbidity and mortality in the Dialysis Outcomes and Practice Patterns Study (DOPPS). Nephrol Dial 
Transplant. 2004;19(1):121-32.

15. Ansarihadipour H, Foolad S. Spectral analysis and structural assessment of human hemoglobin during copper-mediated oxidative stress. Clin Biochem. 2011;44(13):S322-3.

16. Ansarihadipour H. Quantitative analysis for estimating injury effects of metal-catalyzed oxidation on human erythrocytes. Asian Pac J Trop Med. 2014;7S1:S306-12.

17. Benzie IF, Strain JJ. Ferric reducing/antioxidant power assay: Direct measure of total antioxidant activity of biological fluids and modified version for simultaneous measurement of total antioxidant power and ascorbic acid concentration. Methods Enzymol. 1999;299:15-27.

18. Evans P, Lyras L, Halliwell B. Measurement of protein carbonyls in human brain tissue. Methods Enzymol.1999;300:145-56.

19. Ibrahim MA, El-Gohary MI, Saleh NA, Elashry MY. Spectroscopic study on oxidative reactions of normal and pathogenic hemoglobin molecules. Rom J Biophys. 2008;18(1):39-47.

20. Khalifa AS. Physicochemical structure of $\mathrm{Hb}$ in $\beta$ thalassemia. Egypt J Hematol . 1992;15:10-6.

21. Van Biesen W, Vanholder R, Lameire N. The role of peritoneal dialysis as the first-line renal replacement modality. Perit Dial Int. 2000;20(4):375-83

22. Locatelli F, Canaud B, Eckardt KU, Stenvinkel P, Wanner C, Zoccali C. Oxidative stress in end-stage renal disease: an emerging threat to patient outcome. Nephrol Dial Transplant. 2003;18(7):1272-80.

23. Chu P, Cadley M, Bellingham AJ. Red cell metabolism in renal failure--the effect of dialysis. Clin Lab Haematol. 1985;7(1):1-5.

24. Annuk M, Soveri I, Zilmer M, Lind L, Hulthe J, Fellstrom B. Endo- thelial function, CRP and oxidative stress in chronic kidney disease. J Nephrol. 2005;18(6):721-6.

25. Usberti M, Gerardi GM, Gazzotti RM, Benedini S, Archetti S, Sugherini L, et al. Oxidative stress and cardiovascular disease in dialyzed patients. Nephron. 2002;91(1):25-33.

26. Zachara BA, Trafikowska U, Adamowicz A, Nartowicz E, Manitius J. Selenium, glutathione peroxidases, and some other antioxidant parameters in blood of patients with chronic renal failure. Trace Elem Electrolytes Health Dis. 2001;15(2-3):161-6.

27. Zwolinska D, Grzeszczak W, Szczepanska M, Kilis-Pstrusinska K, Szprynger K. Lipid peroxidation and antioxidant enzymes in children on maintenance dialysis. Pediatr Nephrol. 2006;21(5):705-10.

28. Styszynski A, Wieczorowska-Tobis K, Podkowka R, Breborowicz A Oreopoulos DG. Effects of glutathione supplementation during peritoneal dialysis. Adv Perit Dial. 2006;22:88-93.

29. Samouilidou EC, Grapsa EJ, Kakavas I, Lagouranis A, Agrogiannis B Oxidative stress markers and C-reactive protein in end-stage renal failure patients on dialysis. Int Urol Nephrol. 2003;35(3):393-7.

30. Stocker R, Keaney JF, Jr. Role of oxidative modifications in atherosclerosis. Physiol Rev. 2004;84(4):1381-478.

31. Lucchi L, Bergamini S, Iannone A, Perrone S, Stipo L, Olmeda F, et al. Erythrocyte susceptibility to oxidative stress in chronic renal failure patients under different substitutive treatments. Artif Organs. 2005;29(1):67-72.

32. Kir HM, Dillioglugil MO, Tugay M, Eraldemir C, Ozdogan HK. Effects of vitamins E, A and D on MDA, GSH, NO levels and SOD activities in 5/6 nephrectomized rats. Am J Nephrol. 2005;25(5):4416. 